\title{
Motherhood, stress and the exercise experience: freedom or constraint?
}

\author{
JANET CURRIE \\ Faculty of Health Sciences, Australian Catholic University, 40 Edward Street, North Sydney \\ NSW 2060, AUSTRALIA
}

\begin{abstract}
Lack of leisure and time to self have been found to be major stressors for mothers. This paper examines perceived stress-relieving benefits gained from involvement in a 12 week exercise class program by a group of mothers $(n=30, \bar{x}$ age $=37.3$ years $)$. Qualitative data indicated that exercise classes had the capacity to reduce perceived stress levels. The exercising mothers reported greater feelings of well-being mainly due to gaining a space of their own, time-out from busy schedules and the burden of childcare, and the feeling of doing something to improve their physical appearance. The negative or constraining aspects of exercise class participation included normalisation and self examination of women's bodies, and self-surveillance rather than freedom of choice. The conclusions of this paper suggest that exercise classes can provide one avenue for mothers to take more control over their own health and lifestyle.
\end{abstract}

\section{Introduction}

The discourse of normalised motherhood is characterised by women's traditional involvement in unpaid domestic labour within the household and their primary responsibility for childcare. A 'good mother' will train and push herself to maintain a nurturing, yet clean, tidy and efficient household. She will be homebased and will sacrifice her own needs to be selflessly available for her family 24 hours a day. Recent studies have shown that women frequently cite similar features as consistent with 'good' or traditional mothering (Brown, et al, 1997; Wearing, 1984), while others point to inherent difficulties in such an approach (DiQuinzio, 1998; Levy, 1995; Maushart, 1997).

This idea of the enclosure of the individual (mother) in space (home and family) underpins Foucault's (1977) theory of disciplinary technology. According to Foucault, power includes the whole range of disciplinary technologies such as rules, norms, checks and surveillance, which control, transform and condition an individual. An essential part of power includes control of space through limits, prohibitions or obligations. Power acts over the body and over society through the smallest elements, such as the family and through gender relations. Theorists such as Patton (1979) suggest that power is centrally located in one place or state and

Correspondence Address: Janet Currie, Faculty of Health Sciences, Australian Catholic University, 40 Edward Street, North Sydney, NSW 2060, Australia. Email: J.Currie@mackillop.acu.au; fax: + 61297392342 
is not an instrument for oppression, but rather a strategy for training the body. However, wherever there is power there is resistance, or the uprising of knowledges previously discredited. Dominant discourses, such as the ideology of motherhood, are constantly under challenge by individuals who struggle at the conscious or bodily level to create new identities, meanings and subject positions for themselves.

It is therefore not surprising that obtaining adequate mental health and access to leisure are major concerns often expressed by working ${ }^{1}$ mothers (Gjerdingen et al. 2000). According to Smith (1995) and McMurray (1999), mothers are often left with little time to attend to their own health needs and have few opportunities for self-improvement. Lack of exercise, leisure and recreation have been found to be to the detriment of women's mental, social and physical health (Currie \& Develin, 1999; Wimbush, 1986). The reasons for mothers experiencing high levels of stress or anxiety are many; however they are often related to the ethic of care associated with good mothering (Wearing, 1984). The ethic of care is one of the main barriers to women gaining access to sufficient physical activity and leisure (Blair \& Lichter, 1991; Brown et al. 2000; Henderson et al. 1989). Good mothers will remain on-call, putting their own needs on hold.

Wearing's (1990) study revealed a conflict between the most repressive aspects of the dominant discourse on motherhood: the availability of mothers to their children at all times and the rights of children above the rights of mothers; and the cultural ideology of the right of an individual to dignity, justice and autonomy. Strategies used to resist and change the dominant discourse were refusal to cook or do the housework, sharing childcare responsibility with others and refusal to adopt a victim mentality by planning for leisure time. Wearing argued that this presented an opportunity to create a transformed discourse of motherhood, emphasising the right of women to time and space for their own enjoyment and development.

Willming and Gibson (2000) conducted a recent study interviewing a purposive sample of 16 working mothers. Similar to this study's methodology, a constant comparison grounded theory approach was used throughout the interviews and data analysis, and themes were interpreted within a feminist poststucturalist perspective drawing upon a Foucauldian power analysis. The three main themes related to leisure in the lives of working mothers included: (a) freedom of choice as a central condition of leisure; (b) conflicts between work, leisure and family; and (c) resisting \& negotiating the 'superwoman' stereotype.

Using Foucault's (1977) poststructuralist notions of the concepts of power, discourse and resistance, this paper suggests that exercise for leisure offers women an outlet to challenge some aspects of their subordination. The resistance by mothers to take time-out to exercise when they please challenges the ideology of motherhood, or the emphasis of the mother's care for others (Wearing, 1990). It creates a new space that can be reserved just for the leisure of the mother herself. According to Wearing (1998, p.149), this concept of gaining personal space for leisure is defined as:

... space physical or metaphorical over which one has control to fill with whatever persons, objects, activities or thoughts that one chooses. There are many possibilities here. 
A space for one's leisure may take the form of a mental space, such as daydreaming during the vacuuming, a time space such as having a rest in a comfy chair, putting all of the chores on hold, or an activity space, where activities such as walking, coffee with friends or exercise classes may be pursued. This paper examines the possible mental health benefits that may arise for mothers who are able to create active leisure space for themselves. Specifically, it attempts to answer the question, what effect does participation in exercise classes have on the stress levels of working mothers?

\section{Method}

A purposive sample of convenience of 30 mothers was accessed (Patton, 1990). Respondents had to meet inclusion criteria of being a mother of one or more children, and living within the same northern metropolitan area of Sydney, Australia. Mothers responding to an article in a local newspaper joined an exercise group $(\mathrm{n}=30, \overline{\mathrm{x}}$ age $=37.3$ years $)$. With two initial drop-outs, 28 mothers took part in a 12 week, twice weekly exercise programme. The group had a mean of $2.2(\overline{\mathrm{x}}$ age $=10.4$ years $)$ children. Just over half of the group (17 out of 30) stated that they worked full-time at home, and thirteen of this group were involved in some sort of outside employment. All but a few of the mothers in the sample were in married relationships.

The exercise classes were low intensity, low-impact aerobics, involving stepping or walking movements, with no running or jumping. The researcher, with 17 years' experience in women's aerobic class instruction, also led the classes so that no fee would be have to be charged to participants. After a warm-up of 10 minutes, rhythmic movements or callisthenics were carried out for approximately 20-30 minutes. Floor or conditioning exercises focussing on leg and abdominal muscles followed for approximately 10-15 minutes. A final cool-down with stretching to gentle music was then conducted for about 5-10 minutes.

All participants were interviewed individually post the exercise programme. Indepth, audio-taped semi-structured interviews and self-administered written questionnaires containing open-ended questions were used with the group to assist in gaining the participant's point of view, interpretations and meanings as applied to their exercise experience. According to Henderson (1990), leisure is a fluid, holistic experience, and understanding the meanings applied to such experiences is best carried out by qualitative methods.

According to Minichiello, et al (1992), the in-depth interview is an appropriate method to gain access to the individual's words and interpretations. A focus schedule was used for the interview, listing the topics to be covered, including feelings towards the exercise classes, experiences or feelings of stress, and reasons for attending the classes. The interviews and questionnaires used an openended, funnelling questioning technique as recommended by Minichiello et al. (1992). For convenience reasons, questionnaires were completed after the classes, and interviews conducted in the setting of the mother's choice, which in most cases was her home. 
The interview tapes were transcribed verbatim. The use of grounded theory in the analysis of the qualitative data allowed new categories to be discovered (Strauss \& Corbin, 1991). Use of grounded theory in the analysis of the data also meant that the qualitative indicators were derived from the mothers' own responses. By using the mothers' own words and explanations, the findings were based on the mothers' own routinely constructed interpretations of their own social reality:

If the researcher develops theories which are not grounded in the informant's experience of social reality, then he or she runs the risk of constructing and imposing on that informant a fictional view of their reality (Minichiello et al. 1992, p.94).

The coding procedures used to analyse the qualitative data were those as outlined by Strauss and Corbin (1991). Open coding was used to break down the data and label discrete happenings and phenomena with conceptual headings. The concepts were examined, constantly compared and contrasted. Similar events and incidents (concepts) were then grouped to form themes or categories. Once categories were established, axial coding was used to put data together in an attempt to study conditions, characteristics and consequences of particular categories. The qualitative methods used offered opportunities for obtaining individualised responses, expressed needs and diverse opinions in relation to the exercise experience, as summarised in the following section.

\section{Findings}

The main themes to emerge from the interviews and self-administered, written, questionnaires related to how the mothers felt about participating in the classes. The exercise classes were reported by the mothers to have helped in reducing their stress levels and had led to feelings of greater well-being. This was mainly due to gaining a space of their own, time-out from assigned tasks and roles, and feeling as though one was doing something to improve one's body. The main theme which characterised why doing something to improve body shape was able to reduce stress included perceived improvement in an area of the body normally causing the most concern or dissatisfaction. Three mothers felt more stressed from participation due to issues associated with the childcare provided at the class setting, and the effort and organisation necessary to simply arrive on time.

The findings also pointed to a self-disciplining effect of the classes, whereby many of the women wished to improve or normalise the parts of their bodies that they believed deviated from the society ideal. All of the mothers were aware of, and able to compare, when examining themselves, the ideal body shape or image the media often portrays. In contrast to the freedom and relaxation element, a selfsurveillance aspect to the classes was discovered, in that the women were using the class as a body-shaping tool, and they held an expectation that the class would 'deliver' slimming or shaping effects. 


\section{The mediating effect of exercise on stress levels}

One of the main themes to emerge from the qualitative findings showed that the exercise class left many of the mothers feeling immediately less stressed. Exercise was shown to have potential for releasing the stress in mothers and helped all but two of the mothers to 'exercise their stress away', as described by these responses:

Before I was pretty hassled, trying to get there and getting the kids to school and everything, but afterwards ... I just felt cooler in the mind and really good, more in control. (Samantha)

I felt like I had exercised my stress away, [I was] more relaxed, like the things that were worrying me beforehand, I somehow got them out of my system. (Cynthia)

Exercise lets out the stress and helps me to relax. It helps me to relieve my stress, because when I leave work I'm all tensed up, and you know, sometimes I have a headache, and I come to the gym and I'm still thinking about it, but when I start the class I'm concentrating on the class so it all seems to disappear and then my stress is all released. And then I just feel really good. It's sort of like giving me an injection, I'm just sort of really high after I leave the class. (Linda)

Afterwards I feel great for hours and in the long term I feel I'm helping my overall feeling of well-being; must be endorphins or something. (Dawn)

I feel a lot calmer after the class. Exercise helps. It calms me down and helps me focus on other things. I usually feel tense and jittery before the class from getting the children organised for school, [however] straight after the class I feel calm and relaxed, and feel able to cope with the rest of the day. (Julie)

While the mothers who engaged in these exercise classes expressed feelings of mental well-being from the immediate easing of personal stress levels, it is interesting to note that a few mothers stated that this effect was short-lived. They reported feeling tension and stress returning a few hours later once they returned to the usual routine of housework and childcare. Further research needs to be conducted into more long-term or chronic effects of exercise on perceived stress levels.

The mothers in this study who made the commitment to take time out to exercise were able to feel a difference in their lives, in that they felt more relaxed and in control, less frustrated and worried, more optimistic and with improved coping ability. Green (1998) found that leisure contexts provided important spaces for women to review their lives and assess the balance of satisfactions. Recent feminist thought has also helped to re-define motherhood in more positive terms. Mothers can be creative and resilient in finding a variety of alternative strategies as resistance and a source of negotiation with men's power (Collis, 1999). 


\section{The nature of the stress experience}

Approximately one third of the mothers interviewed could be described as aligning themselves with traditional notions of mothering. This proud proclamation was probably the most extreme comment made by one of the mothers:

I feel that I'm a mum: I didn't have the children to be pawned out to someone else. They've never been to day-care ... I get some time when they're in bed, but then I iron and mend and sew. I can't stand to sit still. I'm a good mum who likes to be organised and be on top of things all the time.

I like to be six steps ahead of the kids and everyone else. (Dawn)

The general nature of the stress experienced by most mothers was a feeling of being trapped into a never-ending cycle of household duties that they had to discipline themselves to achieve:

I feel stress from everyday life, being a mother trying to get everything done and mainly getting irritable and tired. (Melinda)

Just uptight and worrying about getting everything done that I want to get done, so that I can feel relaxed in myself. I expect it of myself (Julie).

It's something I haven't done since I had Deanne, you know, to have half a day away from the kids. I keep saying kids, I love them, but to not have any family around, you know, to sort of have a break from the kids a day or a half-day to do whatever I want to do, that would be nice. (Trish)

Little children jumping all over me with not a minute's peace. (Linda)

I often find it hard to cope with a nine month old baby and a husband that works twelve hours a day. Often I get very frustrated and exhausted, muscle tension, tired, headaches. (Maxine)

I try and cram too many activities in my days and I just don't have enough time for everything. (Cynthia)

Another mother said that the pressures of her busy schedule made her feel like a 'non-person':

You feel like you're not a person sort of thing. Everybody comes before you, and you're down at the bottom of the list. I suppose it depends on the individual, too, but that's how I used to feel[before starting the classes]. I used to feel that there was no time for me at all, you know, you'd be lucky in a day if you sat down for a cup of tea. Some days you don't even sit down. I know it sounds ridiculous, but some days were like that. (Ann) 
Main themes to emerge surrounding the mediating effect of exercise on stress

The first reason given by the mothers explaining why they felt less stressed after the class included gaining a space of one's own, as explained by these responses:

Well, once the music starts, and I get into the exercise, I just find that I am in a totally different, you know, space, rather than at work, which you know is really good. I found it was hard, living on the premises, to dissociate from work and so the exercises really helped me in that it helped me to switch off from work. (Ann)

... it makes it easy to forget problems and fantasise. I feel young again, free again, forget everyday life ... now I am pregnant, however, that stay-athome feeling is terrible ... if I'm not able to exercise it adds to that frustrated feeling. (Julie)

... I am away from day to day housework (Maxine).

I've got such a busy life that I find it hard to stop and do nothing. Exercise gives me the time to stop, and not do nothing, but stop and take a bit more time for me. (Linda)

I try to switch off from them. Because I feel that this is my time. And as pressures are mounting up at home you are looking to this more. (Dawn)

This mother's description characterised what exercise classes as a separate space meant to her:

Really Janet, you don't want to know, but to be honest I have a brother who I don't see or hear from due to a feud. Another brother with a life threatening disease. My husband's brother has cancer, another one with medically acquired AIDS. My grandmother had suffered a stroke and is angry and resentful, apart from other problems such as home, income, Christmas, etcetera. I am suffering a lot from stress and I was getting severe headaches ... Yes, the class does help to a degree, I can come here and forget who I really am and escape to another being, another person ... and feel like I'm doing something for myself instead of staying home like a homebound mother. I am feeling my age and feeling young, feeling my body react to exercise and feeling good about myself and my body again. (Julie)

The contrast in the father or husband's ability to take time-out was highlighted by one of the mothers:

... he gets his own time, I mean, he goes for a surf or he'll play golf, and it's different for him, he just sort of walks out of the house. He doesn't have to prepare anybody. You know what I mean? They [husbands] just walk out. 
'Good-bye, I'm going' (laughs). He doesn't have to feed the children or shop for food or cook it or .... (Samantha)

The second theme explaining reasons for experiencing stress relief from participation in exercise classes was time-out. Time-out from assigned tasks and roles was considered important for stress relief, as this mother said:

It is for me- time-out. It makes me think of good things and takes my mind off the stresses. (Rachelle)

Improves my general well-being as the workout releases tension and makes me feel good. Calms me down and helps me focus on other things. (Karen)

Time-out was related to rewarding self, as typified by the following responses. To achieve the reward, a mother has to commit to taking the time-out of her schedule or role as mother:

[I'm] doing something for me, after running around doing everything for the kids I actually feel like I am doing something for me, and I think getting out with other mums and just mixing as a group. (Maxine)

I feel good about myself because I am actually doing it for me and hence feel good all over. Emotionally, it helps you forget about your troubles. So I might arrive feeling perhaps angry or frustrated about something, so decide to take it out on the class and I feel relieved for a while. (Sally)

[The time-out's important] Very. Extremely. At least half an hour to yourself [a day]. Relaxation and well-being for you. Some people get a kick out of getting their hair or nails done. It's a reward. It's something for yourself. And it's for you, whereas it's not for anyone else, you know. Cause you're a mother, and you're a wife, and an auntie ... this [the exercise class] is just for you ... Not enough women do [take time-out] because they're nurturers, they're givers, and you've got to draw the line ... When you're younger you're busy all the time and it's not till you're older that you get to think that, 'Do I want to be healthy longer?'. (Ann)

The feeling of time-out could be achieved through the distraction from the stresses of the day, typified by theses responses:

[The exercise] gives me a break, puts my mind on other things. The class alleviates these feelings of stress as I feel better able to cope mentally and physically. (Rachelle)

The exercise helps me to relax and takes my mind off other problems. (Maxine)

The 'channelling' of one's self into the activity, was explained by another mother: 
Yes, I think they [exercise classes] gave me an outlet because I think I felt I was really heading for a breakdown towards the end of last year; it was becoming so much. Plus your normal pressures of home and having another child that's got needs, plus a husband that's got needs as well. Well, the tension builds up during the day, plus Ben's behaviour was getting so bad before I knew what was wrong with him, that I felt I couldn't go anywhere with him. And that's a terrible feeling when you're stuck with a child who was hyperactive and whingey all day long and you have another little one whose got needs as well. You just feel that you're gonna pull your hair out by the end of the day. I don't know, I just felt that [exercise classes] were something I could channel all my energy into it. (Samantha)

The frustrating effect of not accessing this time-out was explained well in the comment made by this mother:

[The class] helped you cope with day to day matters more easily as well as having time-out for yourself ... aerobic classes make me feel better about myself as a whole, as against the periods that I had been unable to attend. I felt much more frustrated if I was unable to get some form of exercise. (Lorna)

Three disconfirming cases emerged outlining reasons why three mothers felt more stressed after the class. This was mainly due to issues associated with the childcare available, with two mothers describing it as disorganised or, 'a schamozzle'. Another mother felt more stressed beforehand due to her own effort and organisation necessary just to get there on time.

Although complained about at times, an attitude prevailed amongst the group that that it was a mother's ('my') ultimate responsibility to do the caring, cleaning, cooking, and most other unpaid work (Harvey \& Sparks, 1991; Smart, 1985). This internalised norm and resulting impact on behaviour reflects the dominant ideology of motherhood (Hattery \& Fitzpatrick, 2000) or what Foucault (1977) calls, 'docile bodies'. Control of docile bodies, or mothers in the home, includes such disciplinary technologies as the individuation of private space. These spaces may include the kitchen and laundry, or proximity to children. However, in attending the classes, the mothers were able to use the activity as a means of creating a space for themselves for discretionary time-out. Related to the propositions of Foucault, the mothers could potentially use exercise classes as a means to resist the ideology that they should be on-call for household duties 24 hours a day.

\section{Doing something about my body makes me feel better and less stressed}

A final reason why the other mothers felt less stressed was an appreciation and satisfaction gained from the fact that they were doing something to improve their body shape. Body image issues emerged as the major reason or incentive for the mothers joining and continuing the classes (Pearce, 1993):

Yes, I mainly came to the class to try to change my body shape and lose weight. (Samantha) 
I joined because, yes, I'm concerned with my body and wanted to exercise the fat away. (Geraldine)

I did come to the class in an effort to improve my figure and I started on a diet the same day I started the classes and I feel I have toned as well as lost a few Kilos (7 kilograms). (Dawn)

The lower part of my body is overweight. If I were a stone lighter I know I would look better in clothes. Being overweight tends to make you a bit self-conscious when in bathing costumes or shorts. (Lorna)

One mother explained that in the beginning she was looking for the classes to improve the shape of her body closer to its pre-pregnancy form, and then as she felt improvements she looked also for the mental outlet:

I think that just after having a baby, you know, you're trying to get back to what you used to look like, a body thing. I suppose it's a mental thing as well, it was a break from the children. I was looking at it that way then. As your body starts to get back to what it was, you're looking for something else, you're looking at it as a mental outlet, as well as the physical outlet. (Linda)

\section{Perceived improvement in body image}

The qualitative data described ways that the exercise classes assisted mothers to improve their body image, and hence made them feel better about themselves. Related categories included receiving positive comments from others, perceived better appearance, perceptions that the class helped to 'tone', firm or tighten the muscles or defective areas such as a flatter stomach, or weight loss. Typical responses included:

The classes help me think that I'm trying to do something about getting rid of some of the extra weight that I put on through the baby. (Linda)

I feel the classes are working, especially on the stomach. I feel the muscles are getting back to their own self after the birth of my baby. (Trish)

Yes, my legs hurt so it must be working and hubby says I look better. (Geraldine)

\section{Correction of perceived defective body parts}

The mothers often described feelings of well-being and satisfaction gained from perceived improvements with areas of the body normally causing the most concern or dissatisfaction:

I know the classes are helping my stomach and thighs as I feel tight the next couple of days later. (Lorna) 
For me, smaller, tighter bottom, smaller, firmer hips. (Dawn)

On the surface, this seemed to be a positive, healthy and non-competitive approach: the women were enjoying the exercises, smiling and feeling their bodies tone and strengthen up as the program continued. They also didn't seem to be competing with or surveilling each other, which may have reflected the 'down to earth, towel on the floor', community hall-type setting compared with a glitzy, mirror-filled fitness club.

Concerns about body defects and questions on how to 'rid' oneself of them were only reported to the researcher approximately half way into the program (Week 6). To the researcher, this was the moment when she sensed a power shift, or loss of empowerment from the classes for the mothers. A mother questioning the instructor about how to 'get rid of' a flabby stomach had a tense, less happy expression on her face. If the exercise classes were deemed as not helping with body shape improvement, this created tension amongst participants and a degree of increased self surveillance. The categories characterising this phenomena included reports of muscles still feeling slack, flabby or untoned, no apparent weight loss, or the class not focusing enough on areas of the body causing most concern:

This class has been good for all aspects, but may need a few more thigh exercises. (Geraldine)

My stomach does not seem to be getting toned up. I have had two Caesars though, the second being twins. (Trish)

The class does help, but fat in the thighs, stomach and bottom are difficult to move. (Ann)

I have lots of weight to lose, probably $40^{\prime \prime}-28^{\prime \prime}-40^{\prime \prime}$ would be OK- I should probably work harder. (Prue)

\section{Using the class to tone the body and get into shape}

Another theme to emerge indicated a self-disciplining effect of the classes whereby many of the women wished to improve the parts of their bodies that they believed deviated from the society ideal. Ninety-four per cent of mothers in the exercising group constantly expressed the desire to 'tone their bodies' or 'improve their body shape'. These mothers' responses characterised this phenomenon:

I need to get fit again and lose weight and tone up after having a second child. (Maxine)

I need to get in shape after having my baby. (Trish)

Yes, I'm always trying to look better. Like I think I used to. Plus to give me self-confidence. (Lorna) 
I mainly come to the classes to try to change my body shape and lose weight. (Cynthia)

These women were not told by their doctor to lose weight; it was a personal urge or self discipline. Many of the women revealed that exercise classes assisted them, as a form of discipline, in their attempt to try and tone or improve their body shape towards the slim ideal:

When I see myself in my cossie I realise I have to keep going to try and improve my body shape. Tone the fat! (Geraldine)

\section{Perception of the media's portrayal of women's bodies}

The women were also aware, when examining themselves, of the ideal body shape or image the media often portrays. They admitted to feeling pressure to look a certain way. When asked to describe this image, typical responses included:

Big tits, very small waist, no stomach, tight bum, long legs. 20 years at 40 !! (Cynthia)

You are always seeing beautiful, thin women in papers and magazines. Very rarely are the larger women portrayed. Ads on TVs are always slim, tanned, beautiful girls in bikinis. (Linda)

I think the media has a lot to do with influencing women's figures. (Dawn)

Slim, even SKINNY! (Lorna)

Barbie doll images. Still with the tan even though they push block outs and 'Stay out of the sun'. (Linda)

The media portrays an unreal trim, taut and terrific image, thus pressuring young women into eating disorders such as anorexia and bulimia in order to be accepted by peers and the opposite sex. (Ann)

All respondents revealed awareness of the media's constant portrayal of an ideal body shape. The awareness was characterised by the view that it was unlikely that women could achieve such a slim body shape:

Like Elle MacPherson, for instance, the image for which $99 \%$ is an absolute impossibility. (Melinda)

$36^{\prime \prime}-26^{\prime \prime}-36^{\prime \prime}$. Let's give them a chest and a little flesh. I don't want to see gaps between legs and not sticks for arms or legs or bones across chests. (Toni)

They [media] should be portraying optimum health rather than body shape and size. Fitness and endurance rather than skinny versus fat. People should 
be the fittest and healthiest they can be for their natural body size and shape. (Ann)

\section{Expectations that the class deliver results in terms of body improvement}

Despite this general awareness and agreement amongst the women that the mediadriven slim ideal was unrealistic and inappropriate, the mothers still expressed a desire or expectation that the class would 'deliver' to them personal slimming or body shaping effects. For instance, many mothers expressed the need for inclusion of more abdominal exercises. The stomach was also the area most frequently nominated by the exercisers as the body part they were least satisfied with:

I need a lot more work on my stomach, I wish we had more stomach toning specifically. (Maxine)

When women participated in exercise classes, and felt as though they were optimising their body shape, this could have had healthy effects such as improved body image and confidence (Brehm \& Ianotta, 1998). The exercise class could also boost self esteem and confidence if it was perceived as a 'beauty treatment' (Sharma \& Black, 2001). However, studies have shown that social factors such as the media and other women can influence women's perceptions so they internalise the belief that only slim women are successful, sexually attractive and happy with their body shape. For example, a study by Posavac, et al (1998) found that women reported higher weight concerns when they were exposed to media rather than realistic images of female attractiveness.

The mothers were using the class to discipline themselves to lose weight, sculpt body parts and strive for associated goals so they could shape their bodies more closely to a societal ideal (Redican \& Hadley, 1988). Society's emphasis on the slim ideal may mean that women not conforming may feel unattractive or out of place (Bordo, 1992; Shaw \& Kemeny, 1989). Previous research has shown that feeling overweight can make women feel stressed or even depressed (Currie \& Develin, 1999). However other research has shown that low mood can negatively influence one's body image perceptions, that is, women can simply feel heavier if they are feeling depressed (Barber, 2001). A study by Kasper (2001) controlled the effects for overweight by having Body Mass Index (BMI) as a covariate in all analyses. The results suggested that low self-esteem and dysphoric mood increased body image dissatisfaction by making women feel more overweight than they actually were, or creating a larger discrepancy between their own body size and their desired ideal body size. However, exercise participation was involved in this study, and it is widely known for its positive benefits for body image and self esteem (Currie \& Develin, 1999).

\section{Discussion}

\section{Leisure as resistance}

The findings revealed that a reduction in stress is possible through participation in exercise classes. Taking time out from busy schedules to exercise was one way 
that the exercising mothers could resist feelings of entrapment or docility at home. Taking time-out for leisure allows mothers to value themselves and challenge restrictions on personal freedom. It provides an opportunity for mothers to resist the normalising control of stereotyped motherhood discourse. The boundaries of home-bound mothers can be re-defined and reconstructed. Space is fundamental to resistance and the mothers in this study were able to create time-out and a space for themselves. The women in this study felt better after exercise because they felt less stressed and less trapped. This helped them feel that they could cope more adequately with their daily lifestyles. While this study focused on stress-related, health promoting aspects, future studies could discover if such exercise participation can help to re-work gendered power relations.

The prospect of women engaging in leisure purely for pleasure is antithetical to societal expectations that we should put others' needs before our own. A women's sense of self-care through leisure or of her own self-worth has often been eroded. The discourse of motherhood includes acceptable roles, standards, normalised standards and an ethic of care (Weedon, 1987, p.108). Leisure is one aspect of life where mothers can resist definitions of 'mother', 'carer' or 'wife'. In order to create space for such activities, however, women have to negotiate or resist in their interpersonal and other social relations.

Power, according to Foucault, forms knowledge and produces discourse. Resistance can involve uprising of knowledges previously discredited. The establishment of leisure as a valid concept for women, and the popular rising of the notion of leisure as an outlet for mothers to deservedly experience and feel the freedom associated with leisure, are examples of subjugated judgements that have the potential to form alternative and legitimate discourses for women:

The essence of the power relationship is not to discover what we are, but to refuse what we are and to reach toward what we could be, claims Foucault (Wearing, 1990, p.41).

\section{Constraining aspects of exercise participation}

However, for all but a few of this group of mothers, continued participation in the exercise classes also came to be associated with anxiety raising activities, including using the class to discipline areas of their body deemed defective according to the societal ideal. An example here was the women's awareness of the unrealistic image portrayed in the media of a slim ideal, and yet expressing a personal desire to be slimmer and use the class as a means to lose weight and feel more attractive. At the same time as escaping home and mothering obligations, the mothers in this study willingly or unwillingly entered a new trap: the body trap. They increasingly became aware of bodily defects that needed to be improved or removed.

Foucault (1977) described technologies or ways in which power and knowledge are used to maintain the status quo, including examination, observation and normalising judgement. The discipline and normalisation of the female body has to be acknowledged as an amazingly durable and flexible strategy of social control. Women are spending more time on the management and discipline of 
their bodies; producing docile bodies whose forces and energies are habituated to external regulation, subjection, transformation and 'improvement' (Bordo, 1992, p.14). Somehow the women attending the classes felt the urge or desire in their own minds to discipline themselves and join the exercise programme, 'helps me think that I'm trying to do something about getting rid of some of the extra weight that I put on .... Pre-occupation with appearance still affects more women than men, and one effect of this disciplinary power is that we can continue to:

... memorise on our bodies the feel and conviction of lack, insufficiency, of never being good enough (Bordo, 1992, p14).

In this way, the individual recognises themselves in relation to normative discourses. With the examination, the bodily characteristics of the individual are also compared with those of a known group, such as perceived ideals appearing in magazine pictures. The examination is used to measure levels of competence or performance and is also used to impose labels such as 'obese', 'fit' or 'attractive'. Foucault (1977, pp.191-2) describes the examination as a modality of power in which each individual receives status (low or high) and individuality and:

... in which he is linked by his status to the features, the measurements, the gaps, the 'marks' that characterise him and make him a 'case'.

Women attending exercise classes can be caught in a web of surveilling and viewing herself as a 'case' or owning a body with flaws that somehow need augmentation or 'repair'. It is constraining for a woman to distinguish her figure as falling short of the norm for 'beauty' and so feel compelled to attend in order to improve her 'faults': 'I joined because, yes, I'm concerned with my body' or 'yes, I'm always trying to look better'. Mothers can attempt to optimise their own body shape, accept their own biological limitations, gain muscle tone, strength and enjoy the exercise process, or slave towards an ideal only $5 \%$ of the population can realistically achieve. Theberge (1987) warned against the 'femininisation of the fitness movement' resulting in a repossession of women's bodies by emphasising not bodily strength but enhanced sexuality.

Therefore the study's findings revealed a paradox between the freedom or leisure aspects and the self-surveillance or constraining aspects associated with the exercise classes. Exercise classes can exert both a freeing or controlling factor over the women as illustrated in Figure 1. The freedoms and enjoyment associated with the exercise process may be diminished by disciplinary technologies (Foucault, 1977), or pressures and regulations experienced by the mothers to behave or feel in certain ways.

The body can be seen as active, not passive, as it is a social surface of political inscriptions as we live through and are constructed by discourses (Grosz, 1991). The body may no longer be seen as a-cultural as it makes a difference to how we wear and act out gender identity and roles. This transformation from a mind/body split (Grosz, 1991) implies that the mind can't be made useful without the body, and that the body is a site for inscriptions of power and resistance. Complete leisure for mothers requires freedom of mind and body. 


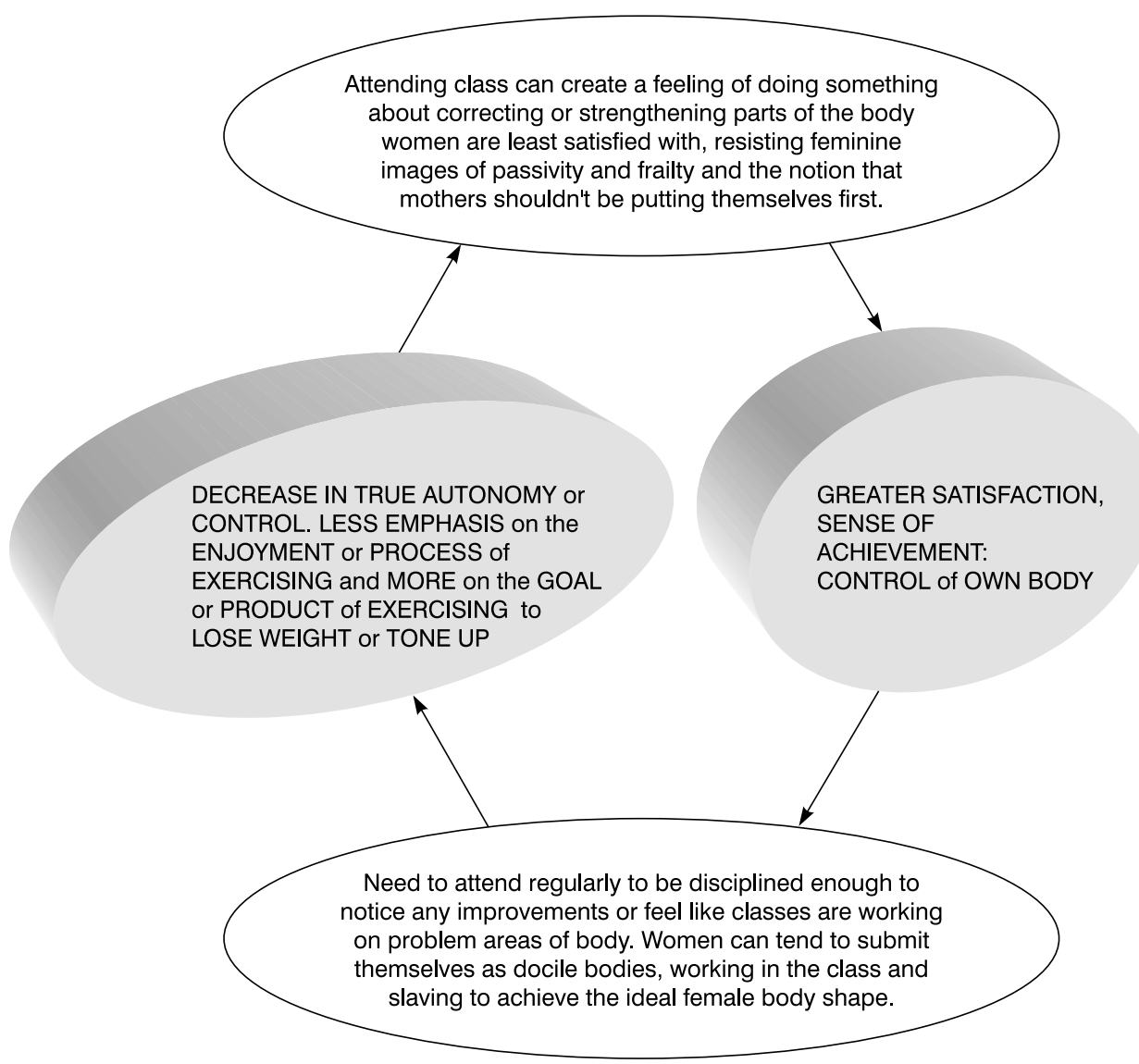

Figure 1. The discipline/control paradox of exercise class participation

\section{Conclusion}

Exercise classes as leisure provide an opportunity for women to resist the normalising gaze of the stereotyped motherhood discourse and an outlet for women to challenge some aspects of their subordination. The re-negotiation and resistance by women to take time-out and make space for themselves by exercising challenges the dominant discourse of motherhood and produces a reexamination of what is considered 'normal'. It also implies empowerment and a greater sense of space for women. Foucault suggests the need for herotopias, those singular spaces found in certain social settings whose functions may be different or the opposite of other such spaces (Foucault, 1984, p.252). Space is fundamental to resistance.

Mothers need to resist and carve out this space and time for daily leisure if they are to gain greater control over their own health and well-being. Research indicates that they may feel greater empowerment, autonomy and self-esteem as a result (Henderson et al. 1989). The study's conclusions concur with Grosz's (1994, p144), when she stated: 
Self-observation can entwine us in various networks of power, but never does it render us merely passive and compliant.

Further, 'power is exercised only over free subjects, and only insofar as they are free' (Foucault, 1982, p221). Mothers are faced with a range of possibilities in the ways they behave. They are not totally dominated by power, as this equates to being a slave in chains (Foucault, 1982). Mothers can accept current lifestyle patterns and social relations, or they can actively seek time-out and new directions for themselves.

Finally, the process of exercise needs to be emphasised for its aspects of enjoyment, individual body optimisation and stress relief. Women need to enjoy the strengthening and liberatory aspects of exercise in contrast to constraining goals of endless body image improvement or feminine concerns for rectification of so-called body part defects. Exercise classes for leisure can be a source of selfnurturance, recuperation and renewal for mothers, if the desire for this space or time-out is materialised via strategies of negotiation, resistance and recognition of self-worth.

\section{Acknowledgements}

I gratefully acknowledge project supervision provided by Dr Betsy Wearing, former Visiting Professor of the School of Social Work, University of New South Wales, Australia.

\section{Note}

1. In this paper, the term 'working mothers' refers to women who carry out paid and/or unpaid work who are also mothers. This is to reflect the valid nature of work conducted in the home, and the fact that women wish to have their legitimate efforts recognised by society. All mothers work, however, for ease of reference, paid work will be noted as 'employment' or 'outside' work.

\section{References}

Barber, N. (2001) Gender differences in effects of mood on body image, Sex Roles, 44, pp. 99-108.

Blair, S. \& Lichter, D. (1991) Measuring the division of household labour: gender segregation of housework among American couples, Journal of Family Issues, 12, pp. 91-113.

Bordo, S.R. (1992) The body and the reproduction of femininity: a feminist appropriation of Foucault, in Gender/ Body/Knowledge, in: A.M. Jaggar \& S.R. Bordo (Eds) Feminist Reconstructions of Being and Knowing, pp. 13-33 (New Jersey: Rutgers).

Brehm, B.A. \& Ianotta, J.G. (1998) Women and physical activity: active lifestyles enhance health and wellbeing, Journal of Health Education, 29, pp. 89-92.

Brown, W., Mishra, G., Lee, C. \& Bauman, A. (2000) Leisure time physical activity in australian women: relationships with well-being and symptoms, Research Quarterly for Exercise and Sport, 71, pp. 206-16.

Brown, S., Small, R. \& Lumley, J. (1997) Being a 'good mother', Journal of Reproductive \& Infant Psychology, 15, pp. 185-200.

Collis, M. (1999) Marital conflict and men's leisure: how women negotiate male power in a small mining community, Journal of Sociology, 35, pp. 60-76.

Currie, J. \& Develin, E. (1999) Stroll Your Way to Well-Being (Sydney: Department for Women, New South Wales Government).

DiQuinzio, P. (1998) The Impossibility of Motherhood: Feminism, Individualism, and the Problem of Mothering (New York: Routledge). 
Foucault, M. (1977) Discipline and Punish, Translated by Alan Sheridan (London: Penguin).

Foucault, M. (1982) The subject and power, in: H.L. Dreyfus, and P. Rabinow (Eds) Michel Foucault: Beyond Structuralism and Hermeneutics (Brighton: Harvester).

Foucault, M. (1984) in: P. Rabinow The Foucault Reader (New York: Pantheon).

Gjerdingen, D., McGovern, P., Bekker, M., Lundberg, U. \& Willemson, T. (2000) Women's work roles and their impact on health, well-being and career: comparisons between the United States, Sweden and The Netherlands, Women and Health, 31, pp. 1-17.

Green, E. (1998) 'Women doing friendship': an analysis of women's leisure as a site of identity construction, empowerment and resistance, Leisure Studies, 17, pp. 171-85.

Grosz, E. (1991) Rethinking the body. Presentation at Body Politics (University of Sydney: Women's Studies Centre Seminar), October 19.

Grosz, E. (1994) Volatile Bodies. Toward a Corporeal Feminism (Sydney: Allen and Unwin).

Hattery, A.J. \& Fitzpatrick, J.J. (2000) Motherhood Ideology and Self-Identity (NCC: Southern Sociological Society).

Harvey, J. \& Sparks, R. (1991) The politics of the body in the context of modernity, Quest, 43, pp. 164-89.

Henderson, K.A. (1990) The meaning of leisure for women: an integrative review of the research, Journal of Leisure Research, 22, pp. 228-43.

Henderson, K.A., Bialeschki, M.D., Shaw, S.M. \& Freysinger, V.J. (1989) A Leisure of One's Own. A Feminist Perspective on Women's Leisure (Philadelphia: Venture).

Kasper, S.A. (2001) The Impact of Self-Esteem and Depressed Mood on Body Image Dissatisfaction (Dissertation Abstracts International: Univ Microfilms International).

Levy, M.J. Jr. (1995) The myth of motherhood: how culture reinvents the good mother, Society, 33, pp. 69-71.

McMurray, A. (1999) Community Health and Wellness: A Sociological Approach (Sydney: Mosby).

Maushart, S. (1997) The Mask of Motherhood: How Mothering Changes Everything and Why we Pretend it Doesn't (Sydney: Random House).

Minichiello, V., Aroni, R., Timewell, E. \& Alexander, L. (1992) In-depth Interviewing: Researching People (Melbourne: Longman Cheshire).

Patton, M. (1990) Qualitative Research Methods and Evaluation (Newbury Park: Sage).

Patton, P. (1979) Power, truth, in: M. Morris \& P. Patton (Eds) Of Power and Prisons in Michel Foucault, pp. 109-47 (Sydney: Strategy).

Pearce, J. (1993) Women's bodies, women's exercise, Australian Journal of Leisure and Recreation, 3, pp. 39-44.

Posavac, H.D., Posavac, S.S. \& Posavac, E.J. (1998) Exposure to media images of female attractiveness and concern with body weight among young women, Sex Roles, 383-4, pp. 187-201.

Redican, B. \& Hadley, D.S. (1988) A field studies project in a city health and leisure club, Sociology of Sport Journal, 5, pp. 50-62.

Sharma, V. \& Black, P. (2001) Look good, feel better: beauty therapy as emotional labour, Sociology, 35, pp. 913-31.

Shaw, S. \& Kemeny, L. (1989) Fitness and wellness for young women: the image paradox, Recreation Canada, 47, pp. 33-8.

Smart, B. (1985) Michel Foucault (London: Tavistock).

Smith, A. (1995) An analysis of altruism: a concept of caring, Journal of Advanced Nursing, 22, pp. 785-90.

Strauss, A. \& Corbin, J. (1991) Basics of Qualitative Research (Newbury Park: Sage).

Theberge, N. (1987) Sport and women's empowerment, Women's Studies International Forum, 10, pp. 387-93.

Wearing, B. (1990) Beyond the ideology of motherhood: leisure as resistance, Australian and New Zealand Journal of Sociology, 26, pp. 36-58.

Wearing, B. (1984) The Ideology of Motherhood (Sydney: Allen and Unwin).

Wearing, B. (1998) Leisure and Feminist Theory (London: Sage).

Weedon, C. (1987) Feminist Practice and Poststructuralist Theory (New York: Basil Blackwell).

Willming, C. and Gibson, H. (2000) A view of leisure and patterns of family life in the late 1990s, Society \& Leisure, 23, pp. 121-144.

Wimbush, E. (1986) Mothers with young children: understanding their leisure needs, Leisure Studies Association Newsletter Supplement: Women's Leisure, Constraints and Opportunities, pp. 13-26. 
Copyright of Leisure Studies is the property of E \& FN Spon Ltd. and its content may not be copied or emailed to multiple sites or posted to a listserv without the copyright holder's express written permission. However, users may print, download, or email articles for individual use. 